\title{
Los spots cinematográficos de imagen real exhibidos en España entre 1957 y 1967
}

\author{
DiAnA RAMAHÍ GARCÍA ${ }^{1}$ \\ Oswaldo García Crespo ${ }^{2}$ \\ Universidad de Vigo
}

Recibido: $03 / 10 / 2013$

Aceptado: 25/05/2014

\begin{abstract}
Resumen
Esta aportación pretende contribuir a la caracterización formal de lo que desde el ámbito académico se ha dado en llamar cine publicitario. Ante la imposibilidad de una empresa totalizadora a este respecto se ha optado por el examen de una muestra espacial, temporal y formalmente acotada, en concreto el análisis de 29 spots cinematográficos de imagen real exhibidos en España entre 1957 y 1967. La selección de este corpus, geográficamente ligado al entorno del investigador, se ha fundamentado en la preponderancia e importancia de la técnica de realización en la producción publicitaria y audiovisual posterior; en las decisivas transformaciones sociales, mediáticas, publicitarias e industriales acaecidas en el periodo: el asentamiento del capitalismo de consumo, la estructuración del medio cine, la modernización de la actividad publicitaria o el surgimiento de la televisión; y en la mayor representatividad de las piezas en una etapa de monopolio sectorial nacional. La articulación del contexto de interpretación se ha edificado sobre el vaciado y contraste de fuentes. El examen del contenido muestral se ha sustentado, por su parte, sobre los procedimientos habituales en el análisis del filme no olvidando en cualquier caso las particularidades industriales, funcionales, discursivas y expresivas de la disciplina publicitaria.
\end{abstract}

Palabras clave: cine publicitario, análisis del filme, España, años sesenta.

\section{Real picture films of advertising cinema screened in Spain between 1957 and 1967}

\begin{abstract}
This paper aims to contribute to the formal characterization of what from the academic field has been called advertising cinema. Given the impossibility of a totalizing enterprise in this regard, we have chosen a spatial, temporal and formally bounded sample, specifically, the analysis of 29 real picture films of advertising cinema screened in Spain between 1957 and 1967. The selection of this corpus, geographically linked to the researcher environment, has been based, on the one hand, on the prevalence and importance of the technique in later audiovisual and advertising production; on the other hand, on the social, media, advertising and industrial mutations that took place on those years: the settlement of consumer capitalism, the emergence of cinema as an advertising media, the modernization of advertising and the arrival of television; finally, on the larger representational possibilities of the films in a national and sectorial monopoly. The research study has been based on the use of authoritative sources and film analysis, not forgetting, anyway, the distinctive features of advertising.
\end{abstract}

Keywords: advertising cinema, film analysis, Spain, sixties.

${ }^{1}$ Doctora en Comunicación Audiovisual por la Universidad de Vigo, desarrolla su actividad docente e investigadora en esta institución desde 2007. dianaramahi@gmail.com

${ }^{2}$ Doctor en Comunicación Audiovisual por la Universidad de Santiago de Compostela, desarrolla su labor docente en la Universidad de Vigo desde 2008. oswaldogarciacrespo@gmail.com 


\section{Presentación}

Si poco después de su surgimiento el texto fílmico se fragmentó en distintos troncos cinematográficos: por una parte, el territorio fílmico colonizado por la ficción, el más importante; por la otra numerosos minúsculos territorios aparentemente secundarios ${ }^{3}$; las últimas décadas del siglo XX pusieron de manifiesto la necesidad de ensanchar la mirada más allá del cine narrativo, hacia el conjunto de los fenómenos culturales y estéticos de los medios ${ }^{4}$.

En esta línea y dado que en esa «vasta provincia cultural» figuran entre otras manifestaciones expresivas la publicidad comercial ${ }^{5}$, esta investigación pretende contribuir, modestamente, a la caracterización formal de lo que desde el ámbito académico se ha dado en llamar cine publicitario.

La amplitud del objeto de estudio, la dificultad en la recuperación del material publicitario, la inexistencia de estudios estéticos previos y las pretensiones de precisión y honestidad investigadoras, han llevado al acometimiento de la empresa en un período temporal, espacial y formalmente acotado, en concreto, los spots cinematográficos de imagen real exhibidos en España entre 1957 y 1967.

La selección de este estudio de caso se deriva de la existencia de una serie de condicionantes tanto endógenos como exógenos. La elección de la técnica de realización -imagen real frente a animación - se basa en su preponderancia e importancia en la producción publicitaria y audiovisual posterior; la limitación territorial se vincula al marco geográfico de estudio; la acotación temporal, se relaciona, por su parte, con las decisivas transformaciones sociales, mediáticas, publicitarias e industriales que se sucedieron en el período señalado: el asentamiento del capitalismo de consumo, la estructuración del medio cine, la modernización de la actividad publicitaria o el surgimiento de la televisión.

A estos criterios de interés investigativo, se unen otros de carácter pragmático relacionados con las limitaciones en la conservación y dificultad de acceso al material muestral, así como meramente operativos, vinculados a la mayor representatividad de las piezas en una etapa de monopolio de la producción publicitaria audiovisual.

El estudio se ha realizado sobre las 29 piezas publicitarias de imagen real presentes en el marco de una muestra inicial de 61 spots cinematográficos, fruto de la catalogación y digitalización - ajena y previa - de los fondos de Movierecord, la principal distribuidora de piezas publicitarias para su exhibición en salas durante esa etapa, en concreto: Los chocolates que gustan... (Nestlé), Acción, misterio, risa... (El niño), Un concurso sensacional (Palmera), Hombres Fuertes (Vitamín), ;Hasta en la sopa! (Culmen), El teatrillo (Balay), Todos los caminos (Mantequerías leonesas), El placer de vivir (Norit), Un modelo tres versiones (Biscuter), De balcón a balcón (Omo), Un jersey Escorpion (Escorpion), Criar niños robustos (Maizena), Contrastes femeninos (Bru), La mujer del día (Omega), Tomando posiciones (Flex), La fórmula (Danamask),

\footnotetext{
${ }^{3}$ Maqua, J. (1995): «El estado de la ficción: ¿Nuevas ficciones audiovisuales?», en Zunzunegui, S. y Palacio, M. (coord.): Historia general del cine volumen XII. El cine en la era audiovisual, Madrid, Cátedra, 201.

${ }^{4}$ Casetti, F. (1995): «La pasión teórica», en Zunzunegui, S. y Palacio, M., op. cit., 112.

${ }^{5}$ Gubern, R. (2005): Historia del cine, Barcelona, Lumen, 36.
} 
La pitonisa (Soberano), El secreto de una estrella (Lux), Fiesta en Bagdad (Sultana), Ritmo y Martini (Martini), ;Oiga, Mire! (Tu tu), Sueño (Nescafé), Strip Street (San Miguel), Ya te contaré de Karrigan (Karrigan), Todo va mejor con Coca Cola (Coca Cola), Caballero Andante (Barreiros Chrysler), Aires de Europa (Iberia), Es cosa de hombres (González Byass), Niña (Chupa Chups)

$\mathrm{La}$ articulación del contexto de interpretación, teniendo en cuenta que la retroalimentación propia de todo proceso comunicativo se deriva tanto en la influencia del entorno sobre la forma expresiva, como en la articulación de ésta como huella, se ha edificado, sobre el vaciado y contraste de fuentes. El examen del contenido muestral se ha sustentado, por su parte, sobre los procedimientos habituales en el análisis del filme ${ }^{6}$ no olvidando en cualquier caso las particularidades industriales, funcionales, discursivas y expresivas de la disciplina publicitaria.

\section{Las transformaciones políticas, económicas y sociales en la España de mediados del siglo $\mathrm{XX}$}

Las décadas de los años 50 y 60 estuvieron marcadas en el estado español por decisivas transformaciones en el contexto político, económico y social, que unidas a una reestructuración de los panoramas mediático e industrial originaron la transformación del modelo que hasta entonces había caracterizado a la producción publicitaria nacional. Fue éste el entorno en el que se configuró y desarrolló el cine como medio publicitario en sentido estricto, y el que se articula como marco de las manifestaciones publicitarias de este período.

La llegada de los años cincuenta supuso un cambio en las circunstancias vitales de los españoles. España modificó su posición en el contexto internacional al ser admitida por la ONU lo que le permitió restablecer relaciones diplomáticas con EE.UU. Ya en el ámbito económico, la autarquía de los primeros años de la postguerra dio paso al liberalismo económico, siguiendo la línea marcada por los gobiernos europeos. Estas iniciales y limitadas pretensiones aperturistas culminaron en la década de los sesenta en el inicio de una etapa de desarrollismo económico y liberalización de las costumbres que se prolongó hasta los años de la Transición. El aminoramiento de las barreras estatales previas, propició la primera gran oleada de multinacionales, el consiguiente incremento en el número de productos comercializados y el definitivo asentamiento de un capitalismo de consumo que modificó la situación económico-social del país. La alimentación dejó así de ser la preocupación esencial de los compradores, dejando paso al auge de valores como la comodidad o el cuidado personal y dando lugar a los consiguientes nuevos mercados publicitarios ${ }^{7}$.

\footnotetext{
${ }^{6}$ Cfr. Casetti, F. y Di Chio, F. (1994): Cómo analizar un film, Barcelona, Paidós; Aumont, J. y Marie, M. (1999): Análisis del film, Barcelona, Paidós.

${ }^{7}$ Conde, F. (1994): «Notas sobre la génesis de la sociedad de consumo en España»,Política y sociedad, 16, 145
} 
La adaptación de la actividad publicitaria al nuevo y complejo entorno, pasó por su propio desarrollo, profesionalización y perfeccionamiento. Se intentó perfilar un ejercicio profesional técnicamente adecuado y estabilizar las estructuras y sujetos vinculados. Al tiempo se incorporaron técnicas propias de la teoría estratégica y la mercadotecnia y el incremento de la competencia aumentó la exigencia ${ }^{8}$.

Por una parte, tuvo lugar el inicio de las emisiones regulares de televisión, que más allá de sus repercusiones sociales y comunicativas, originó un replanteamiento de los pilares mediáticos sobre los que se había asentado la difusión publicitaria hasta entonces. Por la otra, el surgimiento de estudios publicitarios estables y la configuración de la primera $-\mathrm{y}$ por entonces única- red de distribución de cine publicitario en territorio nacional - Movierecord S. A. surgida a raíz de la fusión de Movierecord Ibérica y Estudios Moro- dieron lugar al asentamiento estructural de la publicidad cinematográfica.

En el caso de España, como vemos, las décadas centrales del XX estuvieron definidas por profundas mutaciones en los planos político, económico, social y publicitario. Fue éste el entorno que se contexto de las manifestaciones publicitarias - en nuestro caso spots cinematográficos- de este período, en los que nos centraremos a continuación.

\section{Análisis de los spots cinematográficos de imagen real (1957-1967)}

\subsection{La influencia del entorno en el modelo publicitario. Educación para el consumo y publicidad referencial}

La experiencia previa de otros países había demostrado que una economía moderna no podía fundamentarse de forma exclusiva en la producción en masas, sino que también era preciso enseñar a consumir. Una educación para el consumo que, dado el elevado índice de analfabetismo presente en la España de los años cincuenta y sesenta, era adecuado orientar hacia la publicidad audiovisual ${ }^{9}$ que adquirió, en consecuencia, un carácter marcadamente didáctico y referencial.

Las piezas, de corte eminentemente educativo, carecían de carácter estratégicopersuasivo y de contenido simbólico. Su único fin era crear un entorno, coherente o no, en el que insertar el producto. De hecho muchas de las piezas analizadas a lo largo de esta investigación se caracterizan por la total desvinculación entre el argumento del spot y el producto publicitado, o incluso en la ausencia de una continuidad lógica entre sus diversas partes. Es el caso de Todos los caminos para Mantequerías Leonesas o El teatrillo para Balay.

El cine publicitario se limitaba por tanto a la presentación, no incidiendo por lo general, en aspectos como la creación de imagen de marca o el posicionamiento del artículo anunciado ${ }^{10}$. El mayor o menor acierto del mensaje se sustentaba, por tanto, en su sencillez: historias simples, con una estructura dramática clásica, basada en un

\footnotetext{
${ }^{8}$ PÉREZ, M. (2003): La Transición de la publicidad española. Anunciantes, agencias, centrales $y$ medios (1950-1980), Madrid, Fragua, 141.

${ }^{9}$ EguizÁbal, R. (2004): «El cine publicitario en España», Publifilia, Revista de Culturas Publicitarias, 8,56 .

${ }^{10}$ SÁnchez, M. (2002): Cine y publicidad: creación y consolidación de mundos imaginarios, Tesis Doctoral. Madrid, Universidad Complutense de Madrid, 470.
} 
planteamiento, un desarrollo y un desenlace, que ubicaban al producto en un contexto de consumo, no necesariamente relacionado, al menos en principio, con su receptor potencial. Relatos que en cualquier caso oscilaban entre un corte realista - caso de piezas como Nestlé los chocolates que gustan mucho para Nestlé, De balcón a balcón para Omo o Ritmo y Martini para Martini- y marcadamente ficticio en spots como: Tip y Top ;Hasta en la sopa! para Seguros Culmen, La fórmula para Danamask, Todos los caminos de Mantequerías Leonesas o Fiesta en Bagdad para Sultana.

Fue también este carácter adoctrinador lo que determinó que la publicidad audiovisual de este período adquiriese un contenido marcadamente «referencial» centrado en el producto, sus características y su modo de empleo, en oposición al carácter «estructural» orientado a la sublimación de la marca característico en la publicidad actual ${ }^{11}$.

La mostración del bien promocionado se convirtió en una constante en el cine publicitario de la época, de hecho en nuestro caso, éste aparece en todas y cada una de las piezas analizadas, e incluso en aquellos spots que se refieren a un servicio, éste se materializa a través de un elemento tangible. Es el caso de Tip y Top ;Hasta en la Sopa! para Culmen, en la que aparece el documento que hace referencia al seguro sobre el que versa el anuncio, o Aires de Europa para Aerolíneas Iberia, en dónde el servicio adquiere la forma visual de los aviones de la compañía.

La forma de presentación del producto, y su protagonismo variaron tanto en función de las características y pretensiones de los spots, como en lo relacionado con la evolución temporal. Así, inicialmente su presencia se limitaba a planos contados y específicos, pack shots. Es el caso de piezas como Acción, misterio, risa... de Leche Condensada El Niño u Hombres fuertes para Vitamín que reservan la parte final de su metraje a sucesivos planos de mostración del producto. Con el tiempo el bien comenzó a incorporarse al universo del anuncio, interactuando con el resto de los elementos, bien de forma residual, bien protagónica convirtiéndose en una pieza clave y omnipresente.

Muestra del primer caso son spots como De balcón a balcón para Omo, Contrastes femeninos de Bru, La pitonisa para Coñac Soberano o Fiesta en Bagdad de Sultana, piezas en las que el producto aparece en un momento determinado del relato siendo su presencia aislada. El bien publicitado adquiere sin embargo un papel fundamental en piezas como Ritmo y Martini para Martini, Caballero Andante para Barreiros Chrysler o Niña para Chupa Chups que articulan el producto como hilo conductor narrativo o visual de la historia.

Pero la mostración no resultaba suficiente para una publicidad que debía enseñar al ciudadano no sólo el bien promocionado, sino sus características, propiedades y modo de empleo. Para conseguirlo el cine publicitario optó por sustentar su argumentación en recursos con un importante componente pragmático como la analogía, la solución de problemas o la demostración.

Así, parte importante del corpus analítico se fundamenta en la enumeración de las características y propiedades del producto. Hombres fuertes para Mosto Vitamín, centrada en las óptimas repercusiones físicas derivados del consumo de Mosto; Fiesta en Bagdad para Sultana, que exalta las características de sus «tostaditas» galletas;

${ }^{11}$ CARO, A. (1994): La publicidad que vivimos, Madrid, Eresma \& Celeste, 120 citando a Ibáñez, J. (1986-7): «Una publicidad que se anuncia a si misma», Telos, 8, 117-123. 
Ya te contaré de Karrigan para Medias Karrigan, que hace hincapié en la prolongada duración del producto; o Sueño para Nescafé, orientada a la mostración de las positivas propiedades de la cafeína son ejemplo de ello. Clara muestra es también Criar niños robustos para Maizena, pieza en la que a través de una enumeración se ponen de manifiesto todos los posibles usos de la harina de maíz «Maizena». En este caso, además, el busto parlante infantil recomienda al consumidor potencial la compra de Maizena, incidiendo en la marca y en la necesidad de diferenciarla.

En un intento de superar la referencia exclusiva a las características organolépticas, en otros casos, la utilización se identifica visualmente, en el plano sonoro, o en ambos con situaciones que pueden o deben resultar idílicas para el consumidor. Es el caso de El placer de vivir para Norit en el que se comparan las sensaciones experimentadas en el lavado de la ropa con un paseo por un lago (figuras 25, 26). Similar recurso se emplea en el spot Caballero andante para Barreiros Chrysler, en el que a través de un montaje paralelo se identifica la conducción de un Dodge Dart y un paseo a caballo (figuras 51, 52).

También son frecuentes los spots en los que se reproduce el proceso de utilización del bien o se muestran los resultados del mismo. Prueba de ello son piezas como Tomando posiciones para Flex, en la que se muestran las distintas posiciones que el consumidor potencial puede adoptar durante el sueño; o De balcón a balcón para Omo, que a través de la comparación entre dos coladas pone de manifiesto el poder blanqueador del detergente de la compañía. Similar es el caso de ;Oiga, mire! del detergente Tu-tú en el que se demuestra el poder limpiador del producto en un pañuelo manchado a tal fin.

No faltan tampoco las piezas en las que el elemento publicitado se articula como la solución al problema o problemas señalados a lo largo del spot. Muestra de ello son: Contrastes femeninos para Bru, en el que se suceden diversos episodios cotidianos que muestran las complicaciones que genera el lavado de la ropa y la solución materializada en la lavadora de la marca; Acción, misterio, risa de El niño que, en la misma línea, muestra los inconvenientes que puede generar el consumo de leche líquida, articulando el producto en polvo como el remedio a todos ellos; o La pitonisa para Soberano, en el que una copa de coñac se convierte en la solución para el malhumor y la escasa atención de un marido hacia su esposa.

Son minoritarios, por su parte, los spots orientados a la identificación del producto con un determinado estatus, valor o actitud, antecedentes de la actual orientación estructural de la publicidad. Así, La mujer del día para relojes Omega, vincula el producto a un sector femenino concreto, lo que en el anuncio se califica como «la mujer moderna». Ritmo y Martini para Martini asocia, por su parte, el bien a una situación de entretenimiento, diversión y juventud, del mismo modo que Todo va mejor con Coca Cola, de Coca Cola, en la que el producto, además de articularse como una solución al problema de los protagonistas, se vincula a valores como la diversión e incluso a un estilo de vida marcado por hábitos típicamente americanos como la realización de barbacoas. Similar es el caso de Niña para Chupa Chups, en el que el producto se relaciona con rasgos infantiles. 


\subsection{La influencia del medio cine y los spots cinematográficos}

Aunque en la actualidad asociamos el spot a un entorno de emisión televisivo, no debemos olvidar que la publicidad, visual cinética en primer término, y audiovisual posteriormente, surgió estrechamente ligada al medio cinematográfico. La muestra analizada, manifiesta, en consecuencia, ciertos rasgos aparentemente condicionados por el entorno de emisión.

Así, el spot actual se identifica con un mini-relato de 15,30 o 45 segundos según las fuentes ${ }^{12}$, estándar productivo configurado en gran medida debido a las rápidas pautas y elevados precios de la emisión televisiva. Las piezas cinematográficas de los años 50 y 60 podían, sin embargo, prolongarse durante espacios temporales notablemente superiores, ya que su objetivo no era otro que el de aprovechar publicitariamente los descansos, es decir, promocionar el producto al tiempo que cubrían los entreactos de exhibición. Como reflejo de ello una de las piezas analizadas, Nestlé, los chocolates que gustan mucho, mucho, mucho, se inicia con el cierre del telón y la sobreimpresión «Descanso» haciendo una referencia paródica al entorno de emisión de los spots de la época (figura 1). Así, las piezas analizadas se sitúan entre los 32 - Un modelo tres versiones y Ya te contaré de Karrigan-, y los 177 segundos - Tip y Top hasta en la sopa-, siendo en cualquier caso el estándar dominante aquel que oscila entre los $60 \mathrm{y}$ los 90 segundos de duración y en el que se enmarcan 14 de las 29 piezas de la muestra analizada.

Otros elementos estructurales tan habituales en la época como escasamente usuales desde una perspectiva actual, son los títulos y las didascalias. Cuando hablamos de títulos, no sólo nos referimos a la denominación de la pieza sino a todos aquellos indicios gráficos presentes al principio y al final del filme y que contienen datos relativos al aparato productivo o a las características de la película. 26 de las 29 manifestaciones analizadas presentan este componente fílmico, que contiene en su forma más habitual la denominación, así como la atribución de la autoría, creación y producción de la pieza: realizador/animador, miembros del equipo técnico, agencia y productora. $\mathrm{Su}$ posición - salvo en el caso del título, siempre al principio- oscila entre el inicio y el final del spot, y se sitúa bien en un solo cartón, bien en cartones sucesivos (figuras 19, 20, 29, 41). Del mismo modo, las didascalias, elementos gráficos que integran, explican o separan lo que representan las imágenes, también se hacen presentes en las spots cinematográficos del periodo, y en concreto en siete de las piezas analizadas. En este caso su empleo responde a fines decorativos o de refuerzo del mensaje, situándose en ocasiones sobre la propia imagen y no en cartón aparte (figuras $\mathbf{7 , ~ 8 , ~ 2 1 , ~ 5 0 ) . ~}$

Destaca también, al margen de los condicionantes cinematográficos y en estrecha relación con los publicitarios, el elevado componente textual del cine publicitario de mediados de siglo. Así, la presencia constante de los productos publicitados en pantalla, obliga a la mostración de sus embalajes y multiplica el texto presente en las piezas.

\subsection{La configuración visual de las piezas}

El carácter instrumental que, como hemos visto, adquirió el cine publicitario en la época definió Sus características y se tradujo, en el plano audiovisual, en toda una

${ }^{12}$ Maqua, J. (1995), op. cit., 215. 
serie de elecciones formales tanto intencionales como indeliberadas que acabaron por conformar el modelo publicitario audiovisual de la época.

La muestra analizada manifiesta que las piezas del período se realizaron de forma mayoritaria - aunque posiblemente inconsciente- de acuerdo con lo que en el ámbito cinematográfico se conoce como «modo de representación institucional» ${ }^{13}$ o «modelo clásico de Hollywood» ${ }^{14}$ y en el que todo se encuentra al servicio de la función narrativa. Se optaba así por una puesta en cuadro funcional, la más adecuada para la captación de la realidad representada: predominio de planos frontales de escala variada con abundancia de elecciones intermedias, especialmente planos americanos, medios y de conjunto, tanto estáticos como en movimiento a través de panorámicas, reservándose los planos detalle para la exaltación de las ventajas materiales del producto promocionado. Una planificación visual que en cualquier caso pretendía naturalizarse, optando por fórmulas similares a las que obtendría la mirada humana.

La puesta en serie, por su parte, y siguiendo con la línea mencionada, se apoyaba en el montaje clásico. El objetivo era mantener la continuidad espacial y temporal y resultar lo menos visible posible a los ojos del espectador; lograr, en definitiva, la transparencia del dispositivo. Se utilizaban para ello de forma mayoritaria las transiciones por corte, aunque también hacían presencia fórmulas como el barrido - caso del spot $U n$ concurso sensacional de Hojas de Afeitar Palmera- y la cortinilla - como ocurre en la pieza Acción, misterio, risa ... de Leche Condensada El Niño-, que incrementaban el artificio y la espectacularidad visual (figuras 5 y 6). El fundido, por su parte, se empleaba con valor semántico, como muestra De balcón a balcón del detergente Omo, en el que se usa para resaltar una elipsis.

Sin embargo pese a la aparente adecuación de la fórmula, una modalidad al servicio de la representación, quizás por limitaciones técnicas, temporales o económicas; quizás por ausencia de destreza personal, no se alcanzaron los resultados que había obtenido el cine narrativo, sino que manifestó rasgos propios de los inicios de la cinematografía.

En ciertas piezas las cámaras no consiguen captar la argumentación verbal de los protagonistas al espectador. Es el caso de Criar niños robustos de Maizena, en el que, tanto la portavoz como uno de los protagonistas infantiles se dirigen al espectador, mientras que su mirada se orienta a un punto no coincidente con el de la cámara (figuras 32, 34). En otras ocasiones, caso de Acción, misterio, risa... de Leche Condensada El Niño, Strip Street de San Miguel o Contrastes femeninos para Bru, la sucesión de planos idénticos con una única diferencia de escala entre ellos genera saltos por transformación en la imagen (figuras 35, 36). Por su parte, la aparente ausencia de material fílmico se deriva en la reiteración de planos de escucha. Así, en el spot de Nestlé Los chocolates que gustan mucho se reproduce la conversación entre una pareja por lo que se hace necesario el uso del plano-contraplano. Mientras los planos correspondientes a la parte femenina de la pareja sufren las alteraciones correspondientes a diversos momentos de la conversación, el plano de escucha del hombre es el mismo en los dos turnos

\footnotetext{
${ }^{13}$ Burch, N. (1987): El Tragaluz del infinito. Contribución a la genealogía del lenguaje cinematográfico), Madrid, Cátedra.

${ }^{14}$ Bordwell, D. (1997): El Cine clásico de Hollywood: estilo cinematográfico y modo de producción hasta 1960, Barcelona, Paidós.
} 
de respuesta, lo que se evidencia además por una mirada no justificada a su derecha (figuras 2-4).

En esta misma línea se encuentran aquellas piezas que presentan insertos sin ningún tipo de relación con el resto de los planos. En concreto, en Todos los caminos de Mantequerías Leonesas se incluye un plano detalle de una tarjeta con el nombre de la compañía que no guarda ninguna relación formal y aparentemente tampoco temporal ni espacial con el resto de los planos que configuran el spot (figuras 23, 24).

Por su parte, en otros spots, como Un concurso sensacional de Hojas Palmera, se hace patente la ausencia de determinados raccords. La pieza muestra así como uno de los personajes entra por el lado derecho del coche y en el plano siguiente se encuentra en el asiento izquierdo del vehículo (figuras 11, 12).

Pero más allá de aspectos relacionados con la captación, la puesta en escena también se encargó de evidenciar la ausencia de cualquier tipo de preocupación estética. Según lo observado, la escenificación de las piezas se realizaba bien en entornos reales, interiores o exteriores, bien en decorados a priori adecuados a las características argumentales. La ventaja de los primeros se basaba en la naturalidad que se obtenía al grabar en un espacio preexistente, sin embargo la ausencia de control sobre los elementos internos al cuadro, generaba la presencia elementos visuales no siempre favorables para la promoción del producto. Strip Street para San Miguel muestra diversos planos del asfalto, todos ellos con manchas (figura 47). Por su parte, tanto en Acción, misterio, risa... de Leche Condensada El Niño, como en Criar niños robustos para Maizena, los planos en los que se ve a los protagonistas infantiles comiendo destacan por un realismo antiestético (figuras $\mathbf{9}, \mathbf{1 0}, \mathbf{3 0}, \mathbf{3 1}, \mathbf{3 3}$ ).

Los entornos creados, por su parte, destacaban por su elevado grado de artificialidad. A este respecto resulta paradigmático Contrastes femeninos para Bru, que aúna en una única pieza diversos espacios creados escenográficamente que dan cuenta de serlo (figuras 35-37).

Alas limitadas posibilidades de las localizaciones se unía un aparente desconocimiento de las técnicas de iluminación. Las fuentes de luz se utilizan únicamente para su función primitiva, es decir, conseguir que se vea la realidad representada, pero no se potencian sus valores correctores o expresivos; alumbran, no iluminan. Así, es habitual que en el momento en el que uno de los protagonistas se aproxima a una pared observemos reflejadas entre dos y tres sombras diferentes quebrando la veracidad de la representación. Muestra de ello son Tip y Top ;Hasta en la Sopa! de Seguros Culmen, De balcón a balcón de Detergente Omo o Tomando posiciones para Flex (figuras 22, 27, 38, 42).

En cualquier caso esta desatención hacia los elementos en cuadro que, como vemos, era una constante, desaparecía o al menos se limitaba notablemente, en aquellos planos dedicados a la mostración del producto. En estos casos se ponía especial cuidado en conseguir un resultado visual óptimo que motivase al espectador a la compra. Se recurría a la variedad en la selección de los planos desde el medio al corto y el detalle (figuras 48, 49). El trabajo sobre la composición interna al plano permitía hasta seis posiciones diferentes del producto en sucesivos pack shots en un mismo spot, caso de Todos los caminos de Mantequerías Leonesas u Hombres fuertes para Mosto 
Vitamín (figuras 13, 18). Del mismo modo, se optaba por la pulcritud de la realidad representada, ejemplificada en piezas como De balcón a balcón para Omo, El secreto de una estrella de Lux o La fórmula para Danamask (figuras 28, 45, 46); y por el empleo del movimiento profílmico, a través del uso de plataformas giratorias para posicionar el producto, como ocurre con las cestas de Navidad presentes en Todos los caminos para Mantequerías Leonesas.

No debemos olvidar que, aunque ésta era el marco general que encuadraba el cine publicitario de la época, ya se recurría a otras fórmulas. A la imagen captada en plano único, se unieron recursos como las sobreimpresiones, la pantalla partida o la utilización de material de archivo. Así, La pitonisa de Soberano y Sueño para Nescafé emplean sobreimpresiones. En Es cosa de hombres para Soberano la escisión vertical de la pantalla nos permite visualizar dos realidades que se apoyan mutuamente. Por su parte Hombres fuertes de Mosto Vitamín realiza uso de imágenes preexistente.

Como observamos, se tendió al empleo de recursos que constituían nuevas formas expresivas. Siguiendo esta misma línea se optó por el empleo del plano subjetivo que, con más o menos acierto se repite a lo largo de varias de las piezas analizadas, caso de Los chocolates que gustan mucho de Nestlé, Todos los caminos para Mantequerías Leonesas, Strip Street para San Miguel, La fórmula para Danamask o Niña de Chupa Chups (figuras 44, 43, 53, 54). Ya en el nivel de la puesta en serie, el montaje intelectual hizo presencia Tip y top ;Hasta en la sopa! de Seguros Culmen o Tomando posiciones de Flex (figuras 39, 40), mientras que el paralelo se materializaba en spots como Caballero Andante para Chrysler que posiciona al espectador alternadamente frente a un coche y un caballo con el objetivo de crear una analogía entre ambos. Por su parte, piezas como Ritmo y Martini experimentaron con la sincronización del sonido musical con la planificación e incluso con el movimiento interno al plano.

\subsection{La importancia del plano sonoro}

$\mathrm{Si}$, como hemos visto, en el plano visual se había supeditado la forma al fondo, en el conjunto audiovisual el desequilibrio, también existente, favorecía al componente sonoro. El mencionado carácter adoctrinador del cine publicitario de la época provocó que las diversas manifestaciones sonoras adquiriesen un importante valor expresivo, quizás directamente vinculado a sus inmediatos antecedentes publicitarios de carácter radiofónico. La voz en cualquiera de sus posibles formas-in, off, over- se convirtió en una constante, de hecho únicamente 2 de las 29 piezas analizadas no presentan este componente sonoro. Su función variaba en relación a su ubicación en el contexto de la narración. Así, la voice over, de acuerdo con los preceptos tanto de las piezas noticiosas como de los documentales de carácter expositivo, era la de guiar al espectador a través de la sucesión visual, paliando en la medida de lo posible tanto la polisemia icónica como las limitaciones técnicas y las carencias narrativas en el uso de la imagen que, como hemos visto, eran notables. La presencia de una voz omnisciente facilitaba así la explicación e interpretación de lo observado, ofreciéndole al espectador el significado, o más bien, un significado, el pretendido, de las imágenes. A su vez, su carácter supranarrativo, le otorgaba una posición privilegiada, convirtiéndose en una voz autorizada a ojos del receptor. Posición elevada y externa al relato que en ocasiones se evidenciaba mediante 
interpelaciones a los personajes, caso de Un concurso sensacional para Palmera; o al espectador, en Los chocolates que gustan mucho para Nestlé, Hombres fuertes para Vitamín o Todos los caminos de Mantequerías Leonesas.

Lejos de este carácter institucional de la voice over, las voces diegéticas —la muy habitual interna al plano y la residual en off-se caracterizaban por integrarse en las manifestaciones audiovisuales. Formaban así parte de los diálogos desarrollados en las piezas o de los monólogos que los portavoces presentes en alguno de los spots lanzaban al espectador. Mención especial merecen las emisiones radiofónicas que hacen presencia en Tip y Top hasta en la Sopa para Seguros Culmen, o el hecho de que en algunas piezas la sonorización a posteriori genere desfases e imprecisiones entre el movimiento de los protagonistas y sus palabras. Es éste el caso de Los chocolates que gustan mucho para Nestlé en el que la voz emitida no se corresponde con la articulación verbal de los personajes.

Corroborando la importancia otorgada al plano sonoro, la música también se articuló como una constante en el cine publicitario de mediados de siglo. Su posición fue sin embargo diferente, tanto en el nivel jerárquico como en el funcional, a la del sonido vocal. Debido a la ya señalada importancia de éste último, la expresión musical, exclusivamente instrumental, ocupó un papel secundario en el conjunto de las producciones audiovisuales, adquiriendo una función meramente ambiental en 25 de las 29 piezas analizadas. En cualquier caso, el jingle comenzó a hacer presencia en algunas de las manifestaciones de cine publicitario de la época, fue el caso de piezas como El placer de vivir para Norit, Todo va mejor con Coca Cola de Coca Cola o Es cosa de hombres para Soberano de González Byass; al igual que otras innovaciones expresivas como la ya mencionada influencia musical en el montaje presente en spots como Ritmo y Martini.

El ruido, tercer componente del plano sonoro, siguiendo la jerarquía establecida en las piezas de la época, se caracterizó por ocupar un lugar residual tanto en lo relativo a su presencia y duración como en relación a su función expresiva dentro del conjunto audiovisual. Así, sólo 6 de las 29 piezas analizadas muestran alguna forma de ruido, siendo en muchas de ellas su presencia temporalmente limitada. De este modo muchas de las acciones que ocurren en pantalla carecen del sonido sincrónico correspondiente, ausencia paliada mediante la utilización de la música ambiente e imperceptible gracias al dirigismo de la voice over.

\subsection{Las repercusiones de la evolución técnica. Hacia una publicidad dorada}

Si bien, como hemos señalado, el primitivismo expresivo se articuló como característica general del cine publicitario de imagen real de mediados de siglo, no son menos evidentes las diferencias existentes entre la producción de los años cincuenta y la realizada entrados los sesenta. Todo apunta a la existencia de un perfeccionamiento paralelo a la evolución temporal, quizás los primeros pasos hacia la década dorada de la publicidad española durante los 80 .

Dicha evolución se percibe en diversos factores, el primero de ellos ligado a una evidencia visual: el paso de la realización en blanco y negro a la policromía cinematográfica. Así, el cine publicitario de imagen real se incorporó a la tendencia 
expansiva que la realización en color experimentó durante los años cincuenta, de modo que a partir de los sesenta la realización bicromática clásica fue relegada del cine publicitario, haciendo presencia en 5 de las 29 piezas estudiadas.

Del mismo modo, las transformaciones técnicas parecieron derivarse en modificaciones formales de puesta en forma, en serie y en escena. Aumentó la riqueza en la selección de los planos así como su justificación argumental. El montaje adquirió nuevas posibilidades expresivas más allá de su funcionalidad clásica y contribuyó a incrementar el ritmo visual de los spots. Por otra parte, comenzaron a observarse las repercusiones estéticas de los elementos internos al plano, poniéndose un mayor cuidado en aspectos como la selección cromática o la composición. Todas ellas matizaciones con una influencia estética considerable que se tradujeron en un incremento de la calidad visual de las piezas.

Ya en lo que al contenido se refiere, a medida que la economía de subsistencia daba paso a la sociedad de consumo desarrollista, la publicidad audiovisual perdía referencialidad y ganaba significación. Así, el modelo educativo inicial fue evolucionando hacia un contenido estructural que aunque lejos de la construcción de marca propia de esta vertiente publicitaria, si se encaminada a la asociación del producto con una serie de valores abstractos, no directamente vinculados con sus características organolépticas, pero si con las pretensiones del nuevo consumidor.

Sirvan como ejemplo de esta evolución del spot, piezas como: Caballero Andante para Barreiros Chrysler o Niña para Chupa Chups. En el primero, y como ya hemos referido, el empleo de un montaje paralelo basado en una planificación trabajada tanto en el nivel interno como en relación a escala y perspectiva, permite crear una analogía visual entre montar a caballo y conducir el automóvil publicitado. En el segundo se construye el trayecto de la protagonista mediante una selección visual adaptada de modo preciso a las necesidades narrativas, paralela a una cuidada composición interna al plano. En ambos casos el mensaje se articula en torno a valores no vinculados de forma directa a las características materiales del producto. La pieza de Chrysler se orienta a la transmisión de la libertad y el bienestar que puede generar la conducción, mientras que la de Chupa Chups incide en las consecuencias del producto sobre el carácter de los pequeños consumidores.

Como vemos, el cine publicitario nacional se iba incorporando, a su ritmo, y con sus propias características y condicionantes, a las transformaciones técnicas, profesionales y productivas que se estaban produciendo en el contexto de la actividad publicitaria internacional. Un despegue aparentemente tardío que obligó a acelerar el ritmo en décadas posteriores, condición a priori necesaria para que en un espacio temporal limitado la producción española se convirtiese en uno de los referentes del cine publicitario internacional.

\section{Conclusiones}

El análisis del corpus muestral nos ha permito poner de manifiesto el hecho de que el cine publicitario español de mediados de siglo, inmerso en el proceso de instauración de una sociedad de consumo, se regía por un modelo publicitario de carácter estructural basado en las características y modo de utilización del producto. Las piezas adquirían por 
tanto un carácter expositivo-educativo en el que de forma general, la experimentación cinematográfica y los resultados estéticos ocupaban un papel marginal en relación a los rasgos de los bienes promocionados. Vinculaciones emocionales, valores de marca se articulaban como nociones inexistentes en un contexto social que presenciaba la llegada de ciertos productos por primera vez.

Pero si bien las limitaciones expresivas se articularon como característica general del cine publicitario de imagen real de mediados de siglo, todo apunta también a la existencia de un perfeccionamiento paralelo a la evolución temporal.

Las transformaciones técnicas se derivaron en modificaciones formales de puesta en cuadro, forma y serie. Aumentó la diversidad en la selección de los planos así como su justificación argumental. El montaje adquirió nuevas posibilidades expresivas más allá de su funcionalidad clásica y contribuyó a incrementar el ritmo visual de las piezas. Por otra parte, comenzaron a observarse las repercusiones estéticas de los elementos internos al plano, poniéndose un mayor cuidado en aspectos como la selección cromática o la composición.

Ya en lo que al contenido se refiere, a medida que la economía de subsistencia daba paso a la sociedad de consumo desarrollista, el cine publicitario perdía referencialidad y ganaba significación. Así, el modelo educativo inicial fue evolucionando hacia un contenido estructural que aunque lejos de la construcción de marca propia de esta vertiente publicitaria, si se encaminada a la asociación del producto con una serie de valores abstractos, no directamente vinculados con sus características, pero si con las pretensiones del nuevo consumidor. 


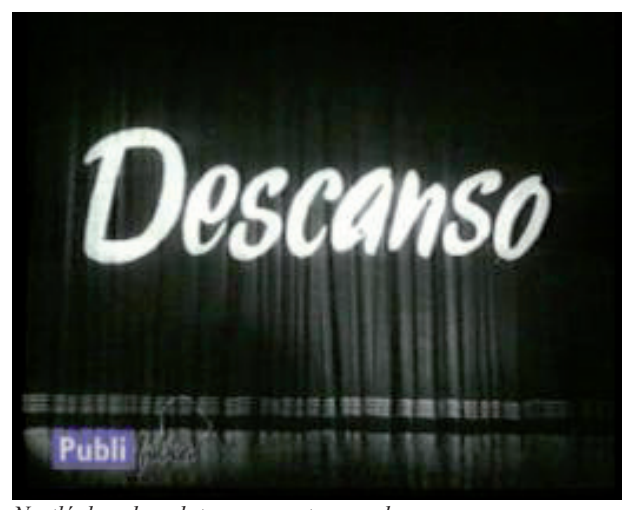

Nestlé, los chocolates que gustan mucho.

Fig. 1

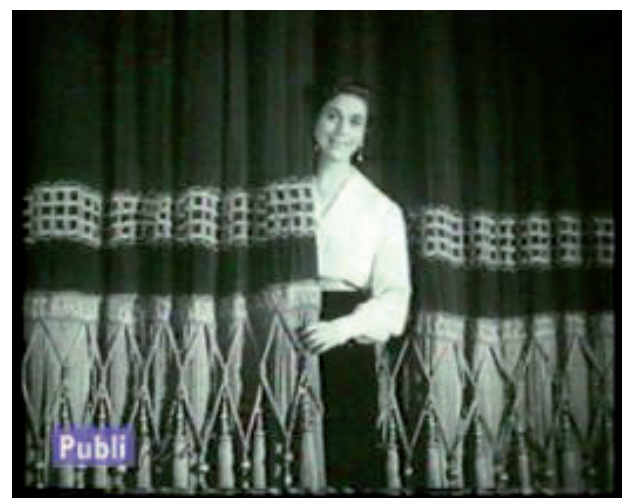

Nestlé, los chocolates que gustan mucho

Fig. 3

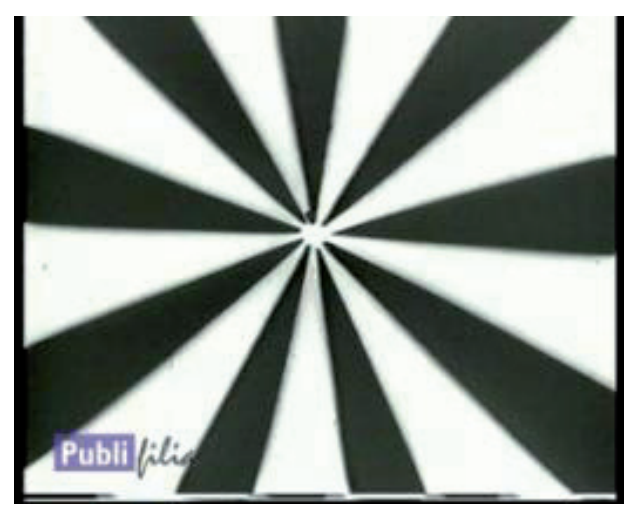

Acción, risa, misterio...

Fig. 5

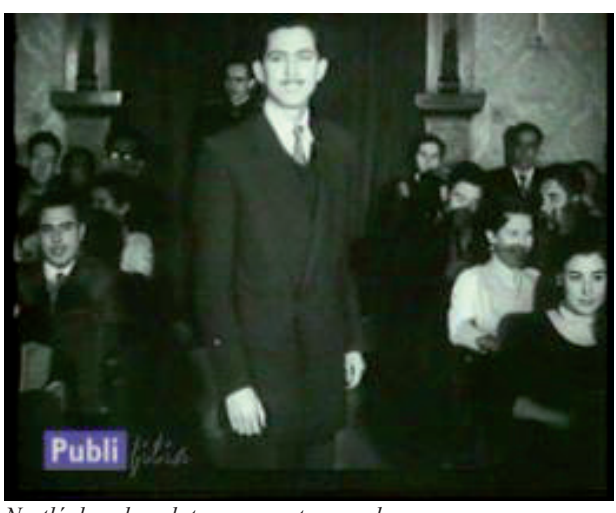

Nestlé, los chocolates que gustan mucho

Fig. 2

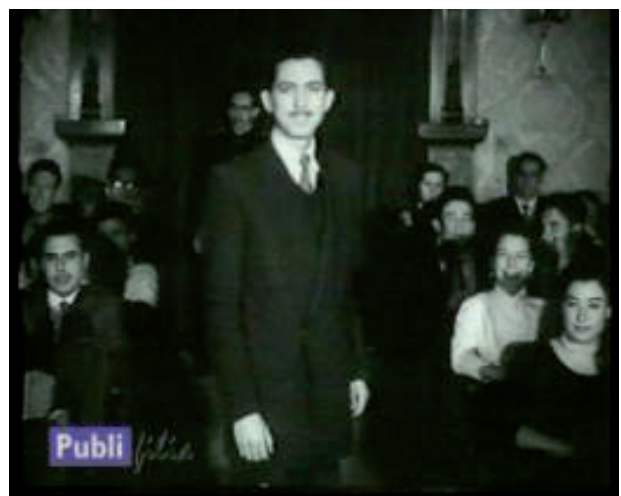

Nestlé, los chocolates que gustan mucho

Fig. 4

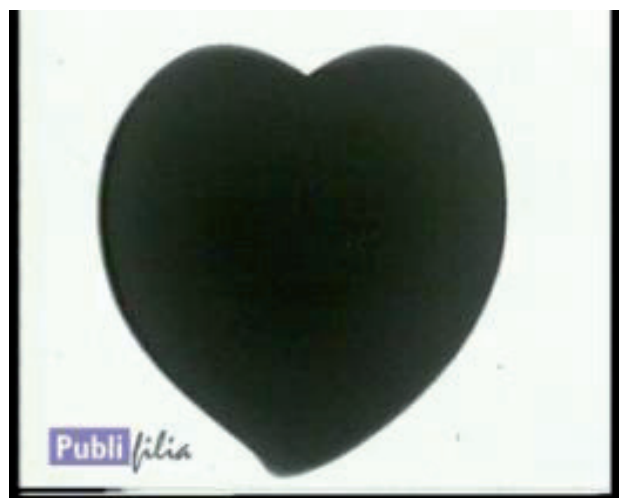

Acción, risa, misterio...

Fig. 6 


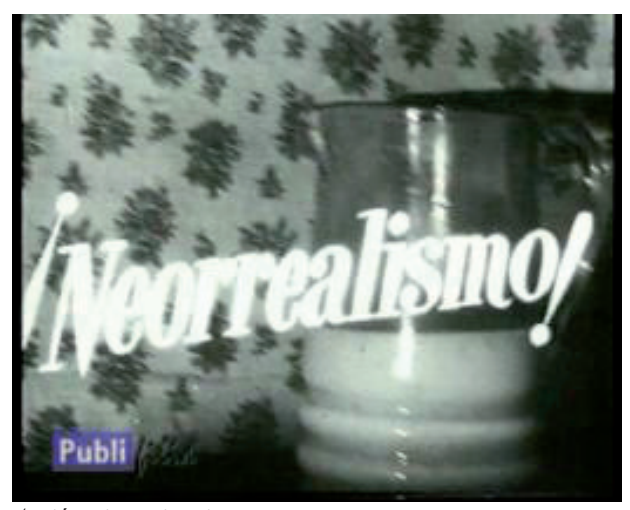

Fig. 7

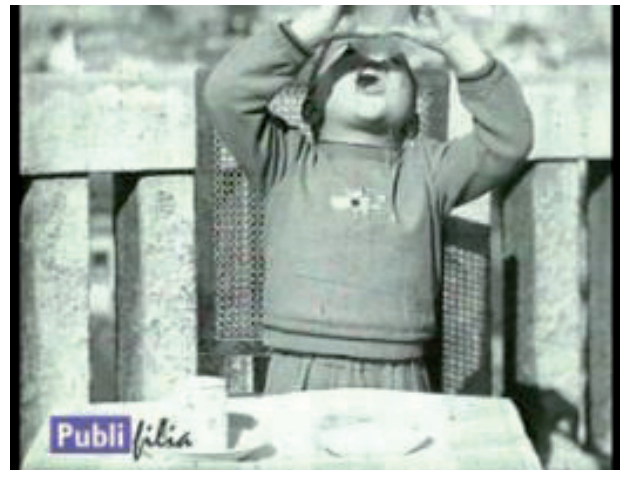

Fig. 9

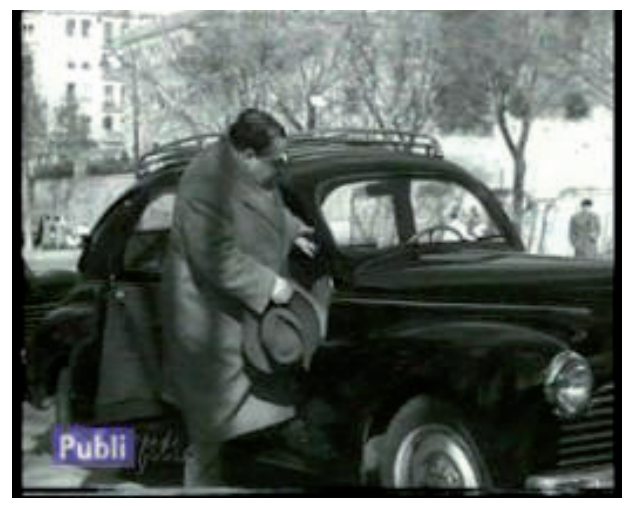

Un concurso sensacional.

Fig. 11

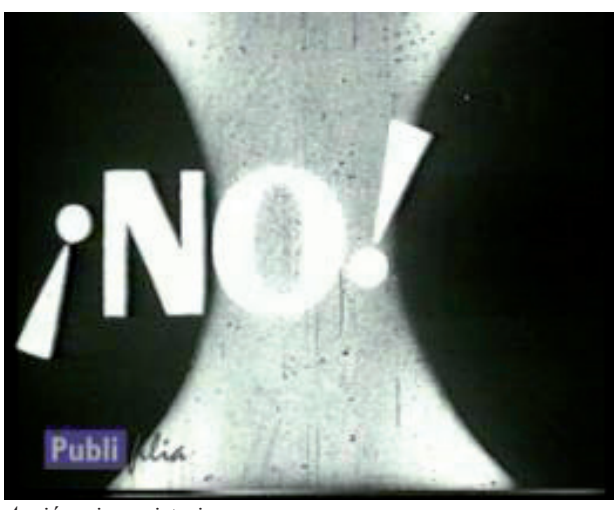

Acción, risa, misterio...

Fig. 8

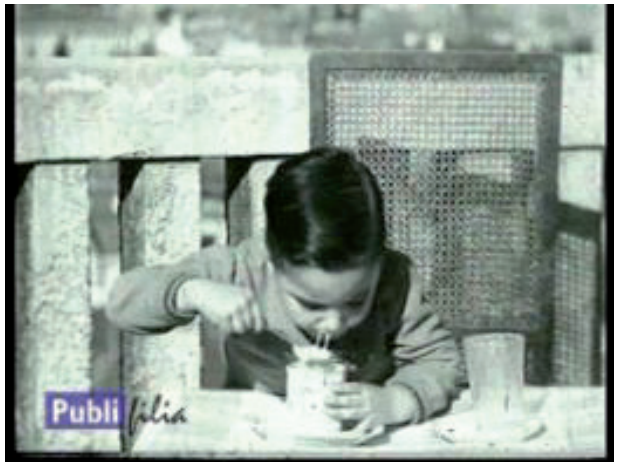

Acción, risa, misterio...

Fig. 10

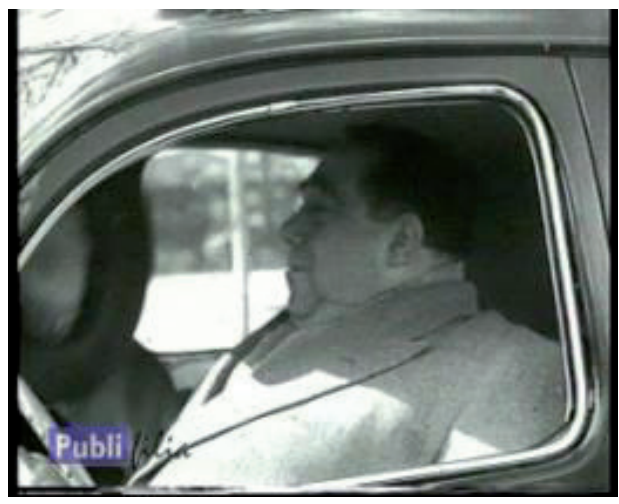

Un concurso sensacional.

Fig. 12 


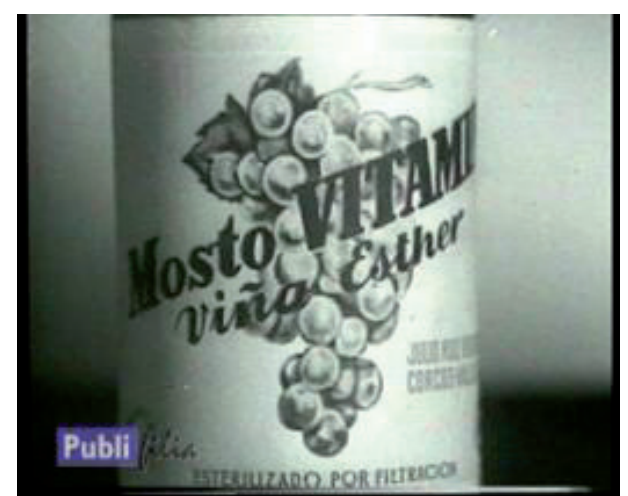

Hombres fuertes.

Fig. 13

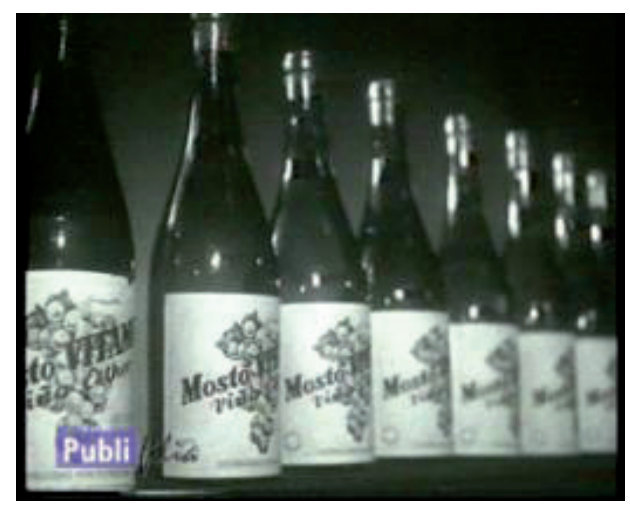

Hombres fuertes.

Fig. 15

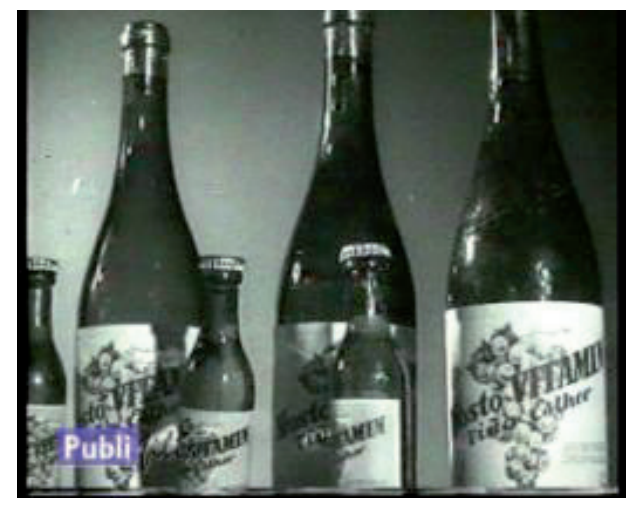

Hombres fuertes.

Fig. 17

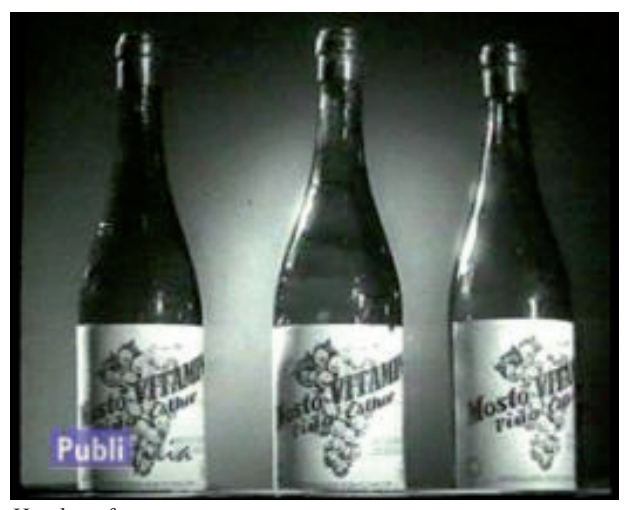

Hombres fuertes.

Fig. 14

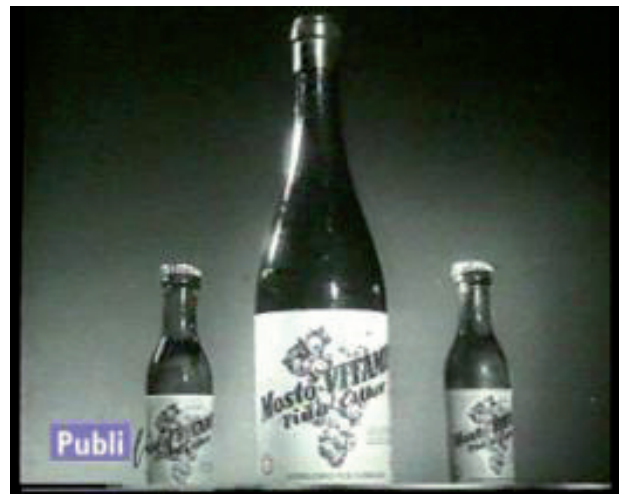

Hombres fuertes.

Fig. 16

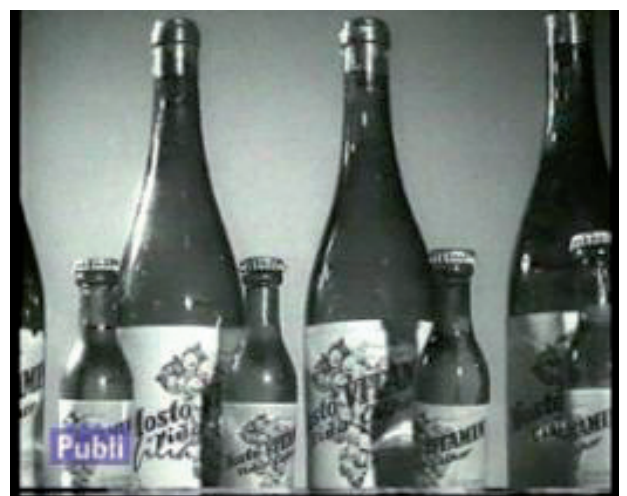

Hombres fuertes.

Fig. 18 


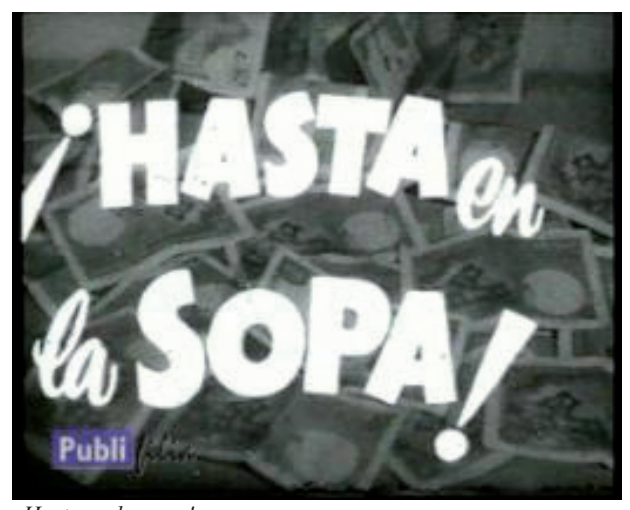

¿Hasta en la sopa!

Fig. 19

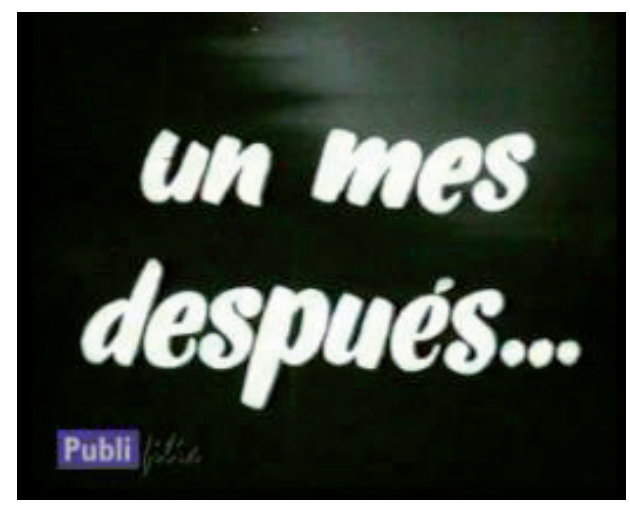

¡Hasta en la sopa!

Fig. 21

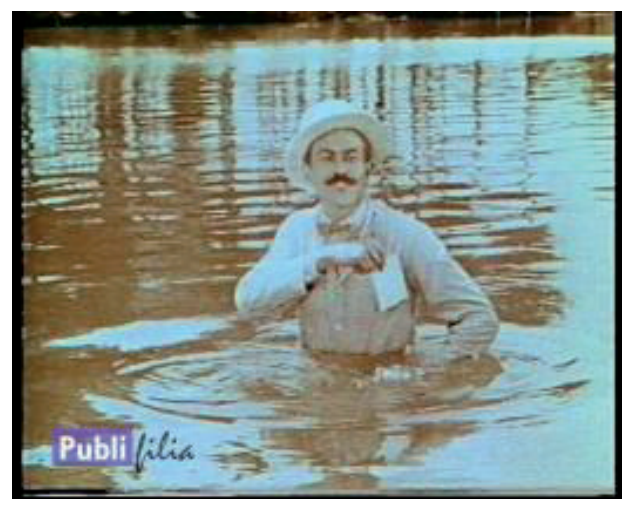

Fig. 23

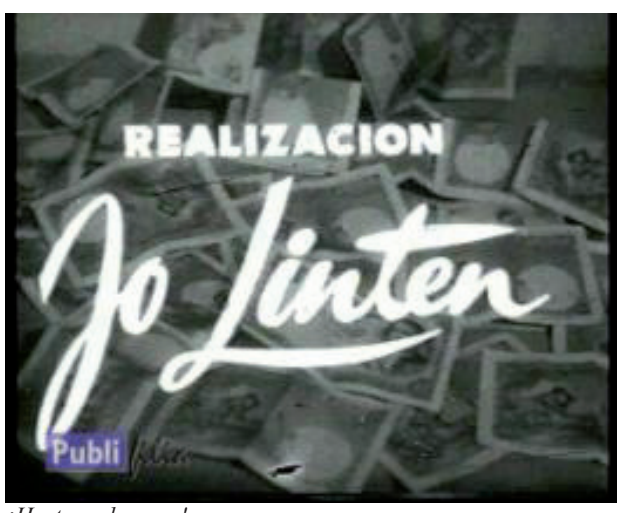

iHasta en la sopa!

Fig. 20

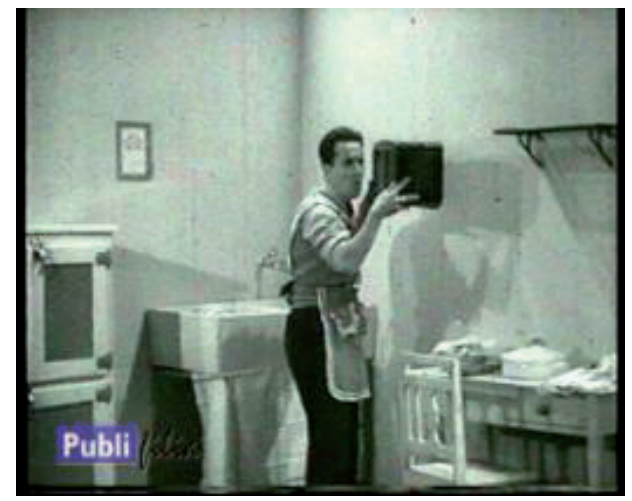

¡Hasta en la sopa!

Fig. 22

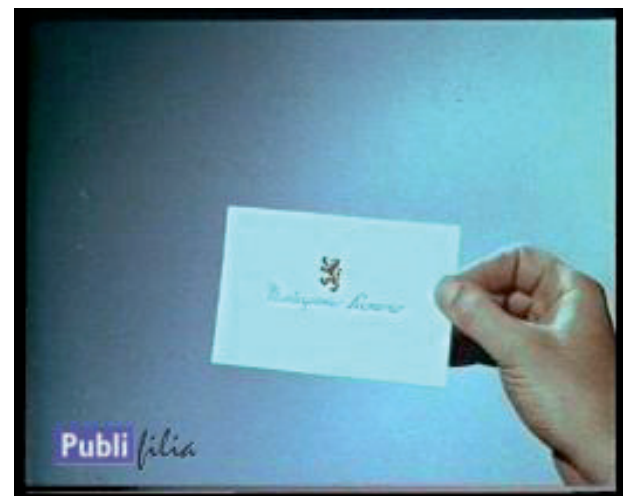

Fig. 24 


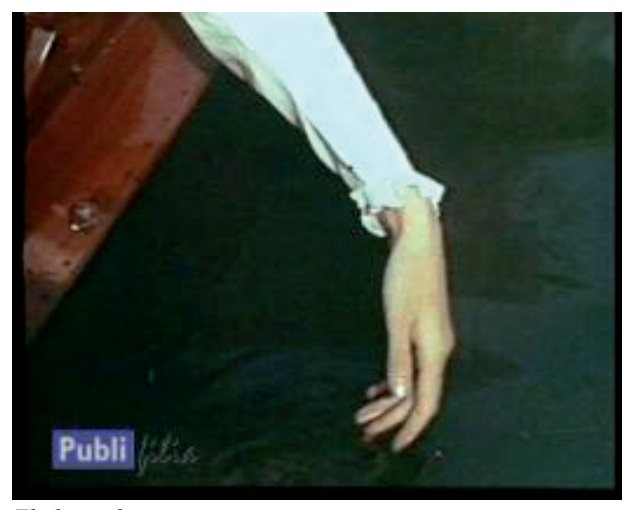

El placer de vivir

Fig. 25

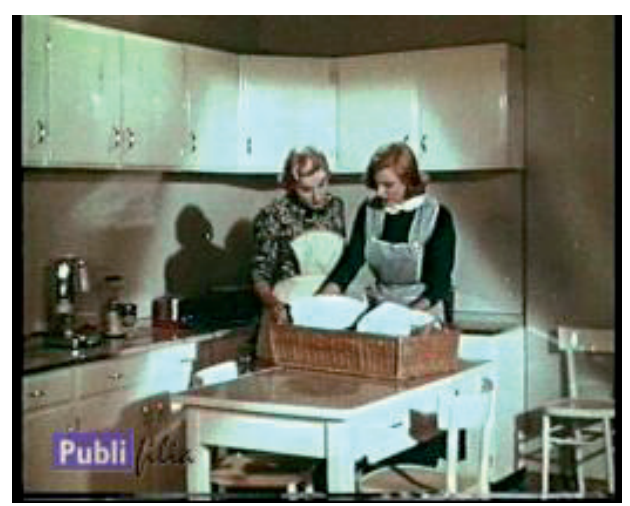

De balcón a balcón

Fig. 27

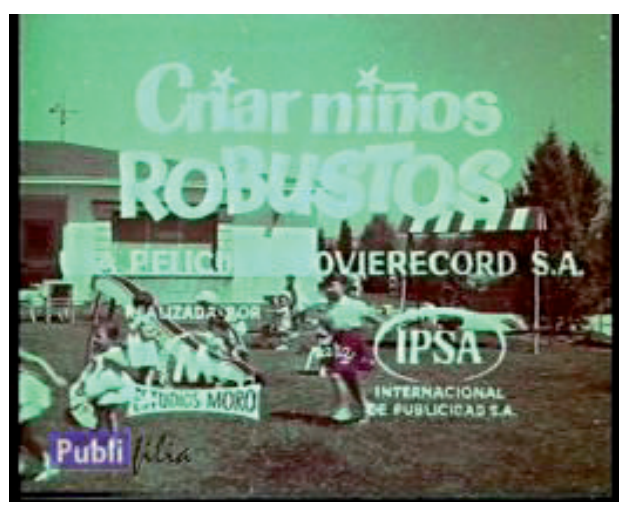

Criar niños robustos

Fig. 29

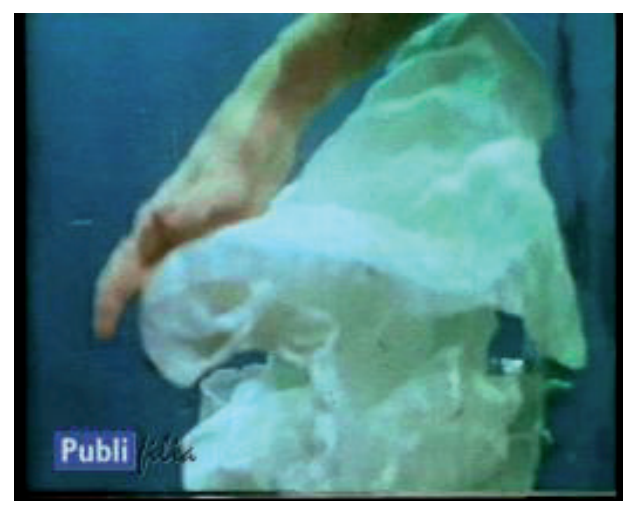

El placer de vivir

Fig. 26

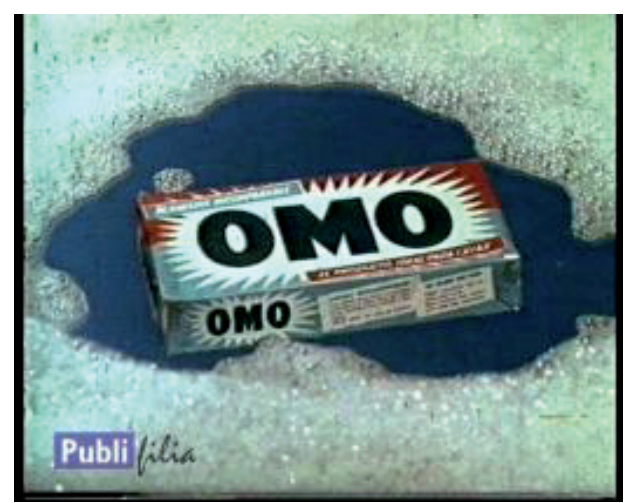

De balcón a balcón

Fig. 28

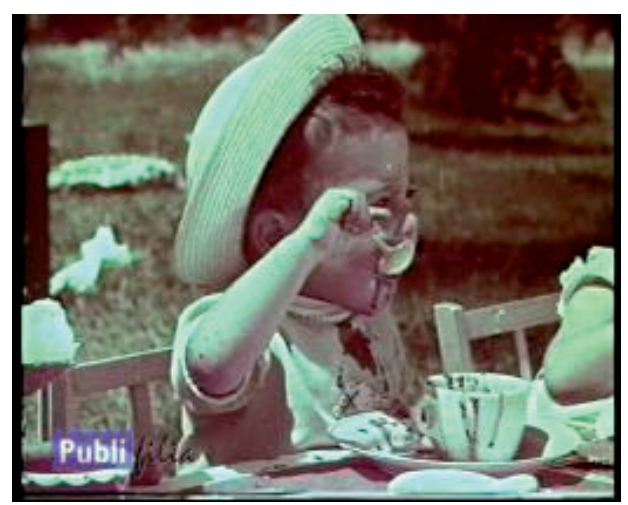

Criar niños robustos

Fig. 30 


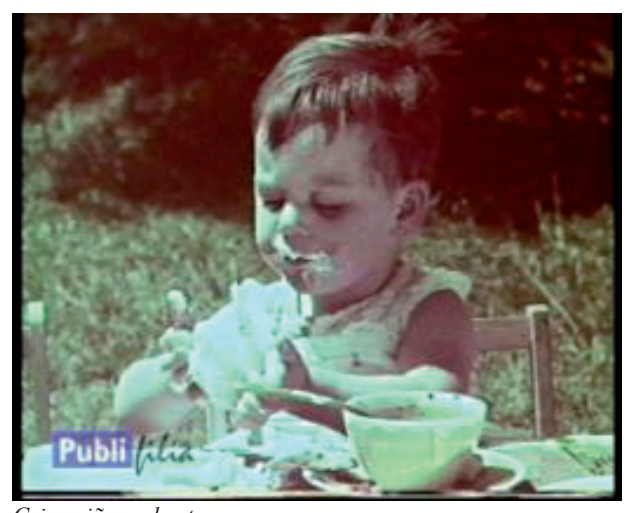

Criar niños robustos

Fig. 31

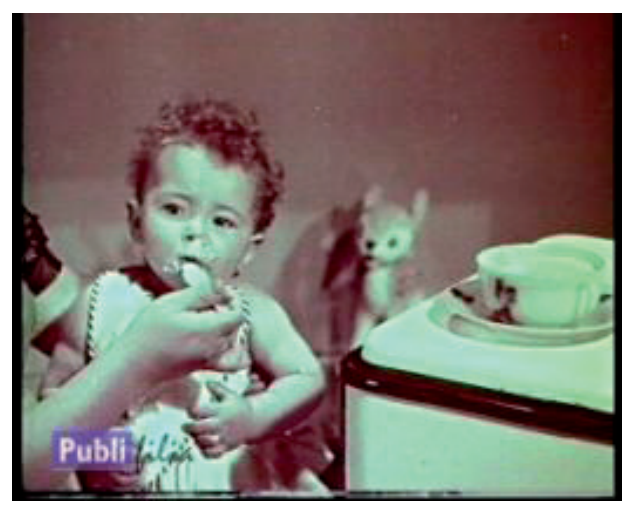

Criar niños robustos

Fig. 33

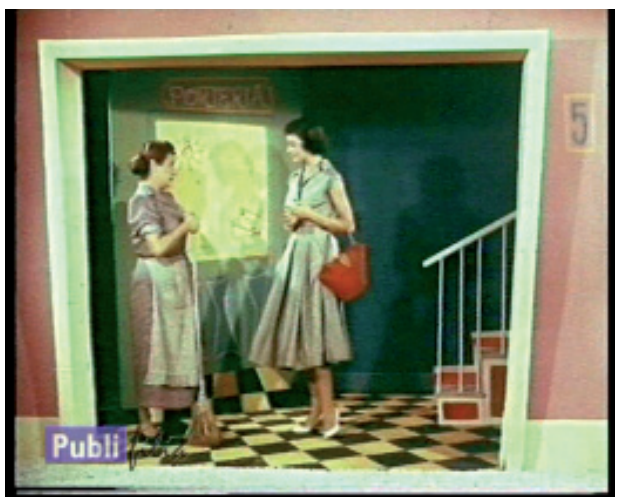

Contrastes femeninos

Fig. 35

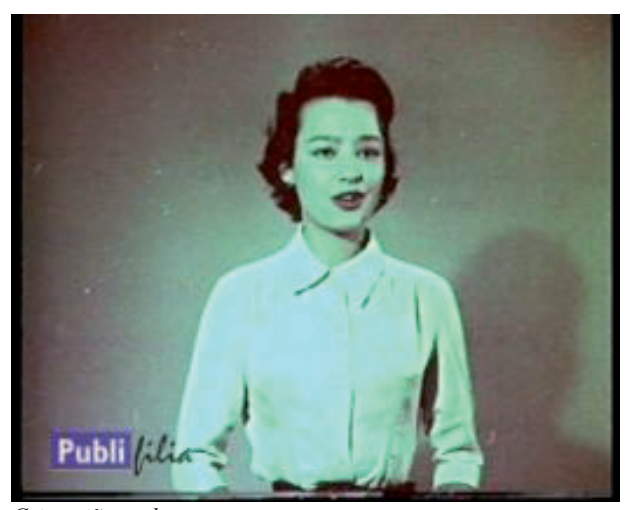

Criar niños robustos

Fig. 32

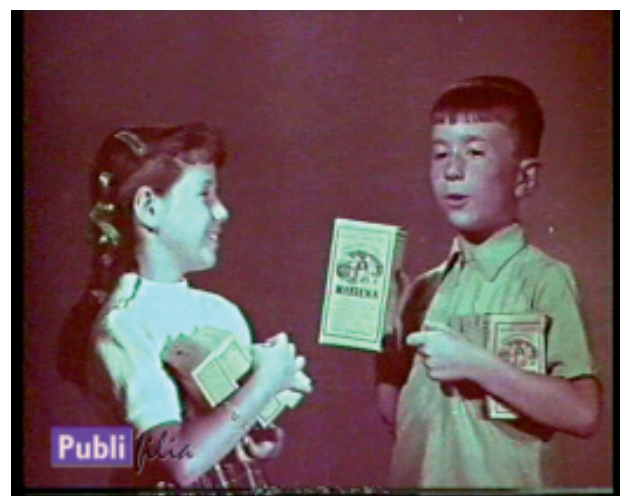

Criar niños robustos

Fig. 34

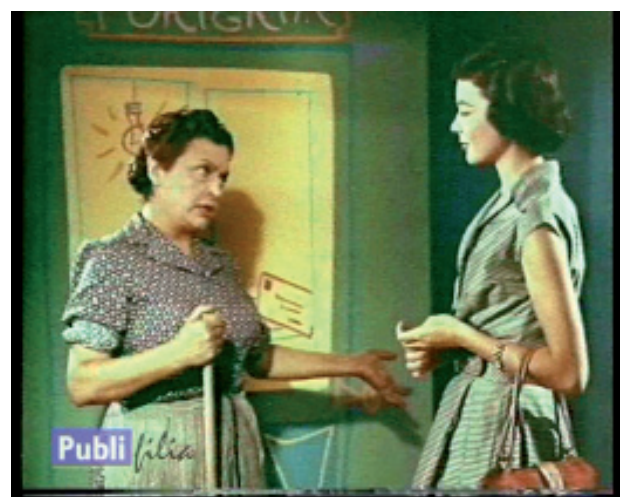

Contrastes femeninos

Fig. 36 


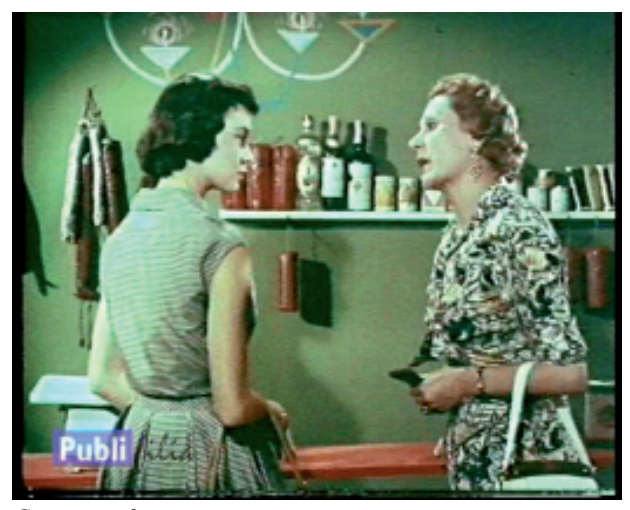

Contrastes femeninos

Fig. 37

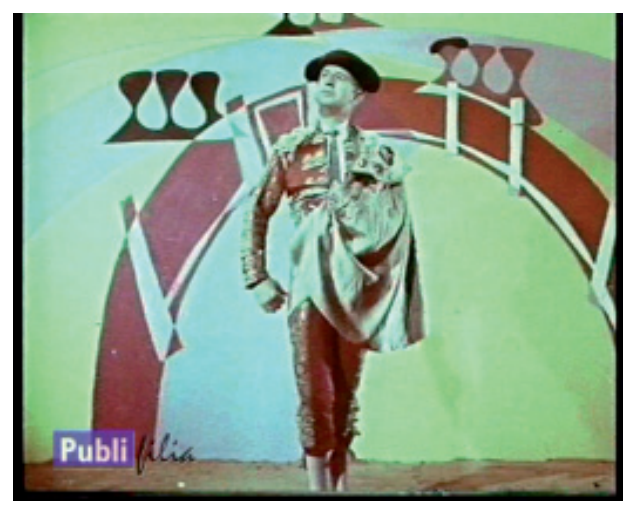

Tomando posiciones

Fig. 39

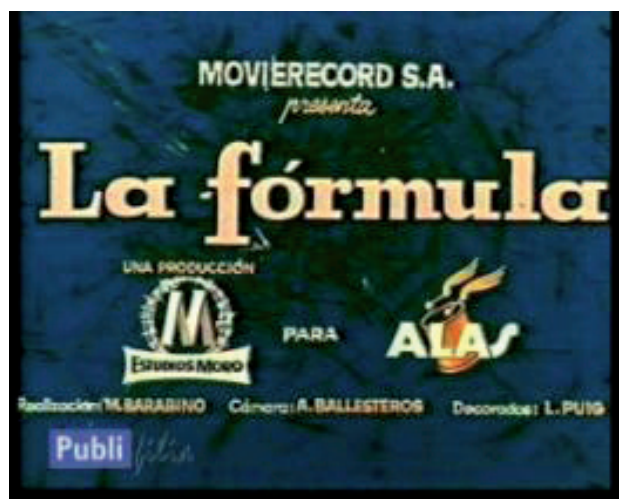

La fórmula

Fig. 41

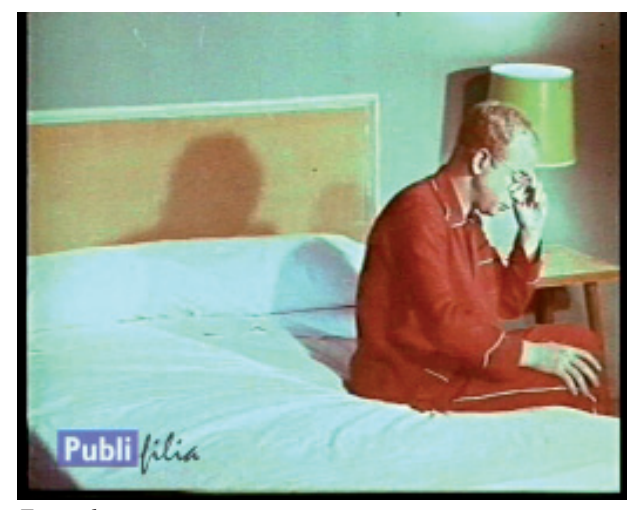

Tomando posiciones

Fig. 38

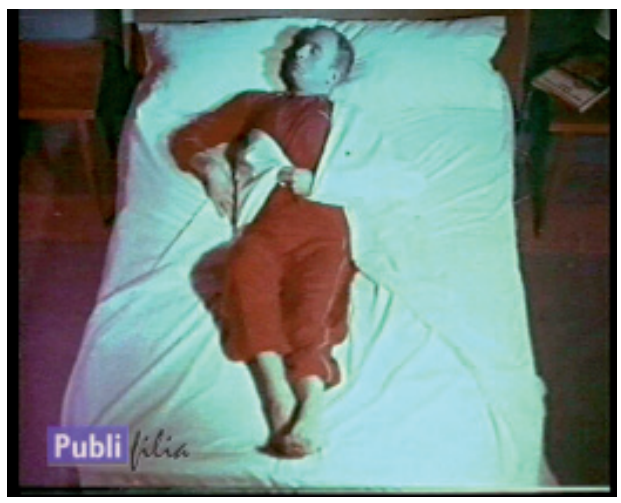

Tomando posiciones

Fig. 40

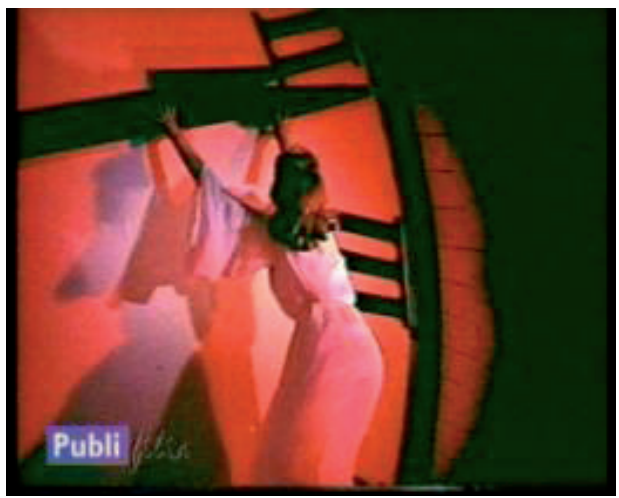

La fórmula

Fig. 42 


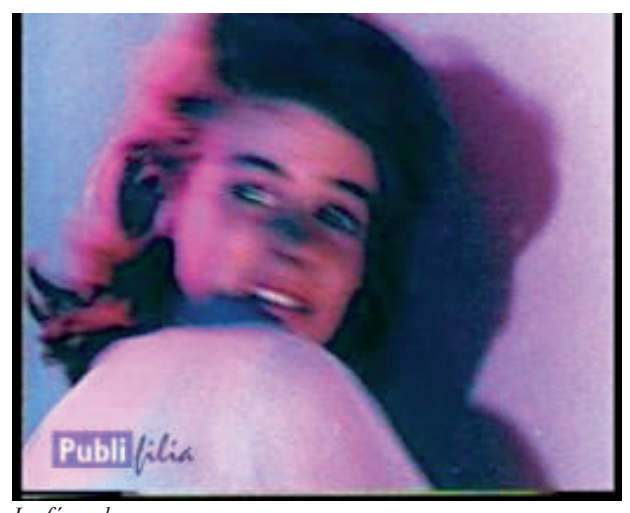

Fig. 43

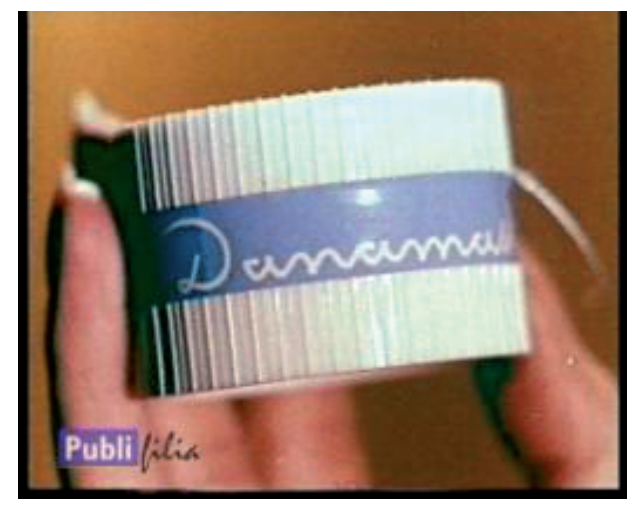

La fórmula

Fig. 45

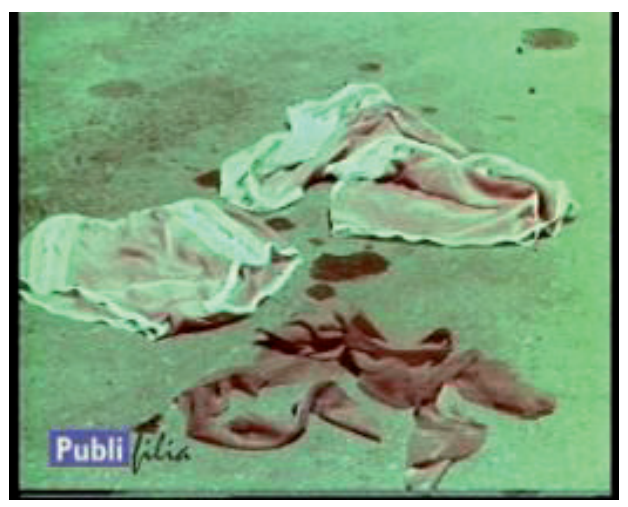

Strip Street

Fig. 47

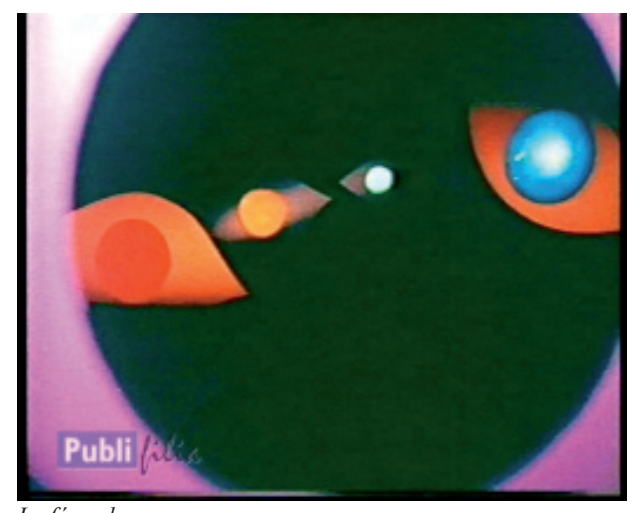

La fórmula

Fig. 44

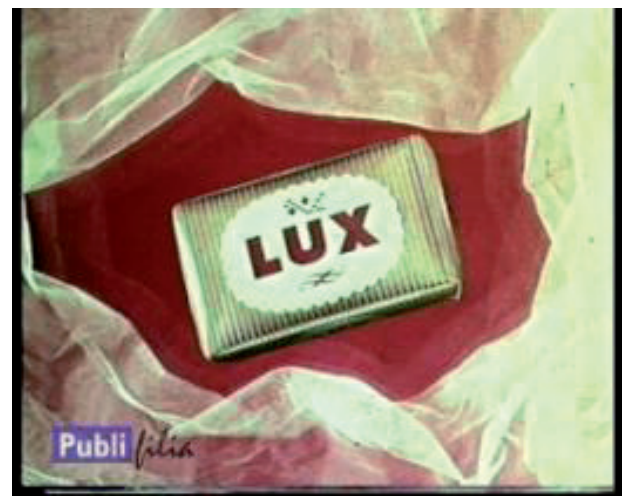

El secreto de una estrella

Fig. 46

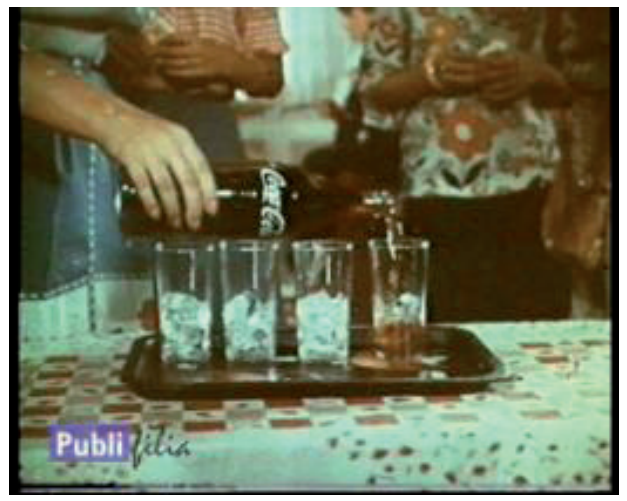

Fig. 48 


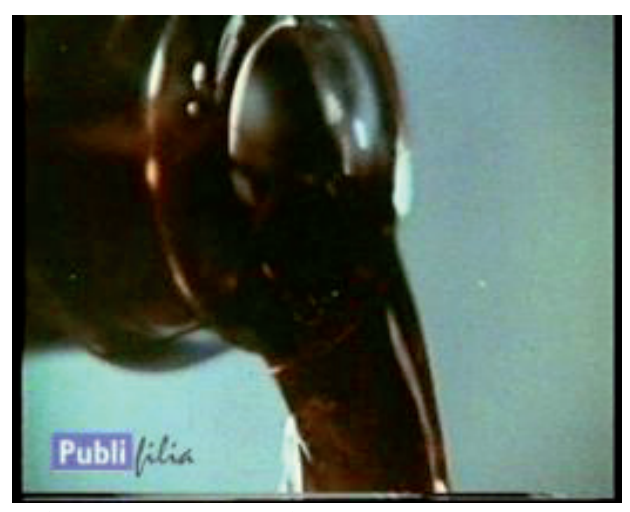

Todo va mejor con Coca Cola

Fig. 49

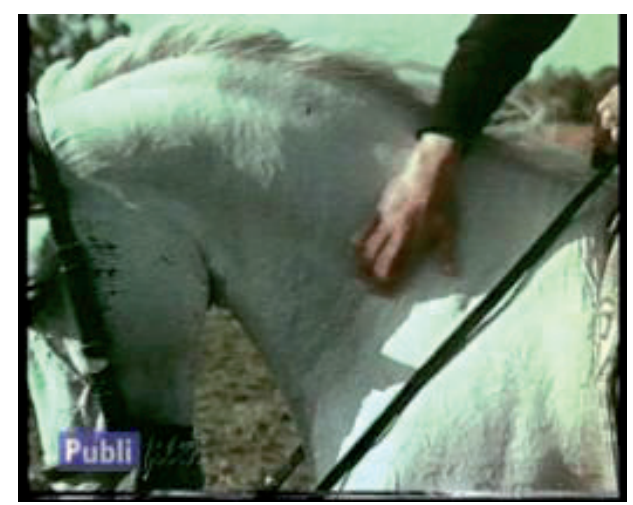

Caballero Andante

Fig. 51

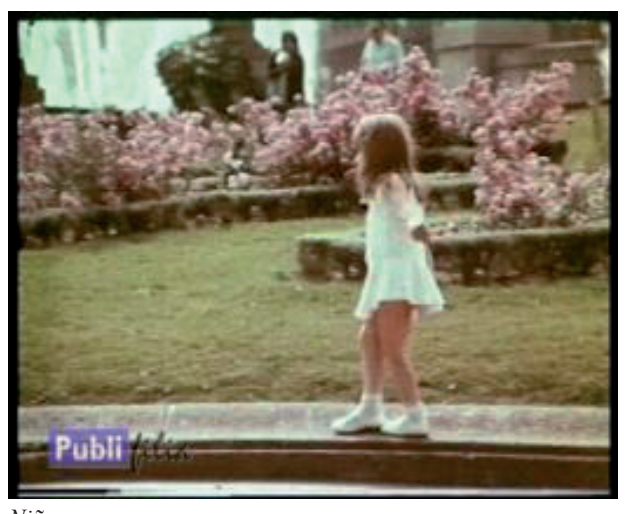

Fig. 53

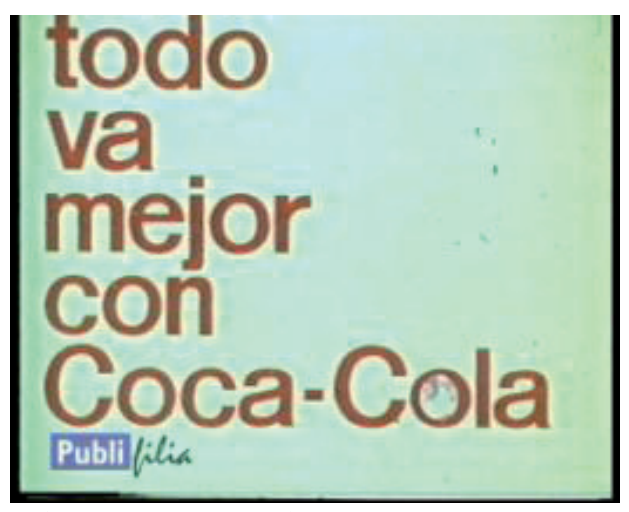

Todo va mejor con Coca Cola

Fig. 50

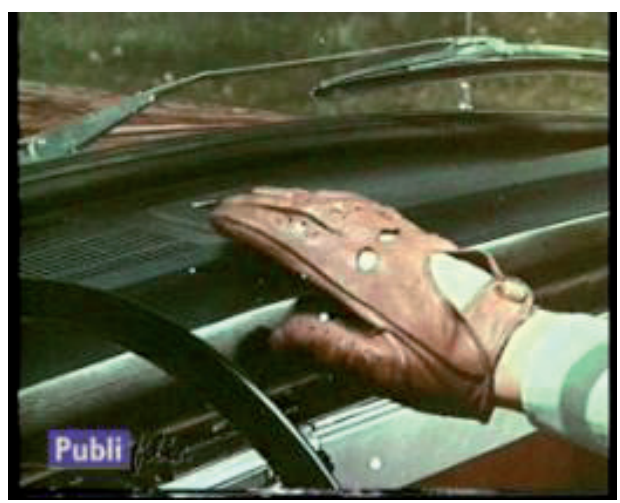

Caballero Andante

Fig. 52

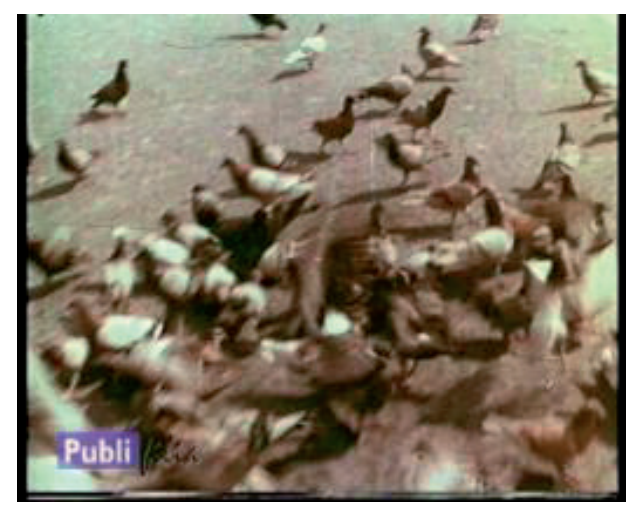

Fig. 54 


\section{Bibliografía}

Aumont, J. y Marie, M. (1999): Análisis del film, Barcelona, Paidós.

Bordwell, D. (1997): El Cine clásico de Hollywood: estilo cinematográfico y modo de producción hasta 1960, Barcelona, Paidós.

Burch, N. (1987): El Tragaluz del infinito. Contribución a la genealogía del lenguaje cinematográfico), Madrid, Cátedra.

CAro, A. (1994): La publicidad que vivimos, Madrid, Eresma \& Celeste.

Casetti, F. y Di Chio, F. (1994): Cómo analizar un film, Barcelona, Paidós.

Conde, F. (1994): «Notas sobre la génesis de la sociedad de consumo en España», Política y sociedad, 16, 135-148

EguizÁbal, R. (2004): «El cine publicitario en España», Publifilia, Revista de Culturas Publicitarias, 8, 37-68.

EguizÁbal, R. (2006): «El cine publicitario en España. $2^{\text {a }}$ Parte (años 70 y 80)», Publifilia, Revista de Culturas Publicitarias, 9, 5-25.

Gubern, R. (2005): Historia del cine, Barcelona, Lumen.

IBÁÑEZ, J. (1986-7): «Una publicidad que se anuncia a si misma», Telos, 8, 117-123.

Pérez, M. (2003): La Transición de la publicidad española. Anunciantes, agencias, centrales y medios (1950-1980), Madrid, Fragua.

SÁnchez, M. (2002): Cine y publicidad: creación y consolidación de mundos imaginarios. Tesis Doctoral. Madrid, Universidad Complutense de Madrid.

Zunzunegui, S. y Palacio, M. (coord.) (1995): Historia general del cine volumen XII. El cine en la era audiovisual, Madrid, Cátedra.

Publifilia (2004): Cine publicitario en España. Décadas 50 y 60, Segovia, Colegio Universitario de Segovia, DVD. 